\title{
Vitamin D metabolites and analogues, diphosphonates, danazol, and bromocriptine
}

\author{
COLIN R PATERSON, JOHN FEELY
}

Our understanding of the physiology of vitamin $\mathrm{D}$ has been transformed in recent years; one consequence has been the development of analogues which are considerably more potent than vitamin $\mathrm{D}$ in the treatment of hypoparathyroidism and of azotaemic osteodystrophy. The treatment of symptomatic patients with Paget's disease of bone has advanced with the establishment of the role of calcitonin and more recently with the introduction of the diphosphonate drugs. Recent experience with bromocriptine confirms its place in the treatment of the prolactinomas, and its list of indications has grown to include parkinsonism and the suppression of lactation. Recently, the medical treatment of endometriosis has advanced with the use of danazol, which may be given to suppress gonadal function.

\section{Vitamin $D$ analogues and metabolites}

Vitamin D (calciferol) is now recognised as a precursor for the production by the kidney of a hormone, calcitriol $(1,25-$ dihydroxy-vitamin $\mathrm{D}_{3}$ ), responsible for active calcium absorption in the gut. Calcitriol (Rocaltrol) is effective in promoting calcium absorption and raising the plasma calcium in patients whose endogenous calcitriol production is impaired. This is the case in renal failure, in hypoparathyroidism (parathyroid hormone is required for the 1-hydroxylation step in vitamin $\mathrm{D}$ metabolism), and in a rare inherited disorder, vitamin $\mathrm{D}$ dependent rickets. In these disorders calcitriol is effective in microgram doses compared with the milligram doses needed with native vitamin $\mathrm{D}$.

A useful analogue of calcitriol is alphacalcidol, $1 \alpha$-hydroxyvitamin $\mathrm{D}_{3}$ (One-alpha). This is hydroxylated at the 25 position in the liver to give calcitriol; as with calcitriol, microgram doses are effective in patients with hypoparathyroidism or with renal failure. Both drugs increase the plasma calcium concentration in a newly diagnosed patient with hypoparathyroidism in a few days.

While the speed of action of calcitriol and alphacalcidol is an advantage compared with that of calciferol itself, this very speed may contribute to the ease with which patients can be poisoned by an unwary physician. As with poisoning with vitamin $\mathrm{D}$, the hypercalcaemia may cause permanent renal damage and soft

Ninewells Hospital and Medical School, Dundee DD1 9SY

COLIN R PATERSON, DM, FRCPATH, senior lecturer, department of biochemical medicine

JOHN FEELY, MD, MRCPI, lecturer, department of pharmacology and therapeutics

Correspondence to: Dr Colin Paterson. tissue calcification. Since the half life of calcitriol in the plasma is about three hours appreciable fluctuations in plasma calcium concentrations are likely to occur in patients who take the drug irregularly, and for most patients preparations with a longer half life, such as alphacalcidol, dihydrotachysterol, or even calciferol itself, are preferable.

Dihydrotachysterol (AT 10) has long been recognised as an effective alternative to calciferol. It has a shorter half life than calciferol and requires only a 25-hydroxylation in the liver to produce a metabolite that mimics the action of calcitriol. Its use has so far been limited by the awkwardness of its administration (in liquid form), but it has recently become available as tablets (Tachyrol).

\section{CHRONIC RENAL FAILURE}

Many patients with chronic renal failure have bone pain, muscle weakness, increased plasma alkaline phosphatase activity, and histological evidence of osteomalacia which is largely due to a failure to produce calcitriol from calciferol. A widely held view is that only symptomatic patients should be treated with alphacalcidol or calcitriol with a usual daily dose of about $2 \mu \mathrm{g}$. Symptomless patients with radiological and biochemical evidence of osteodystrophy (subperiosteal erosions and increased plasma alkaline phosphatase activity) respond to treatment with alphacalcidol within a year, but hypercalcaemia is common and difficult to prevent. Long term treatment with alphacalcidol is less effective; the bone disease in some patients worsens despite continuing treatment. In patients with normal hand radiographs who are undergoing regular haemodialysis hyperparathyroidism may be prevented by giving small doses $(0.25$ to $0.5 \mu \mathrm{g}$ daily) of calcitriol. The prophylactic use of alphacalcidol and calcitriol in patients not undergoing dialysis has been less successful and is often complicated by hypercalcaemia. Patients undergoing haemodialysis who do not respond usually have some other reason for continuing osteomalacia, such as aluminium toxicity.

\section{HYPOPARATHYROIDISM}

The newer preparations, particularly alphacalcidol, are indicated in the initial treatment of a symptomatic patient in whom speed in correcting the hypocalcaemia is needed. For patients already well controlled with calciferol no change should be made. For long term treatment calciferol and dihydrotachysterol seem equally valuable. With both drugs constant vigilanceincluding estimations of plasma calcium concentrations at least every four months-is essential. The place of alphacalcidol in long term management is unclear; although it may be used 
effectively, it is not known whether with careful control problems are more or less likely to occur than with calciferol.

\section{OSTEOMALACIA AND RICKETS}

Calcitriol, alphacalcidol, and dihydrotachysterol are not indicated in nutritional osteomalacia. Vitamin $D$ remains the drug of choice, either by mouth or by a single depot injection. In patients with osteomalacia due to malabsorption (including patients with long standing obstructive jaundice) parenteral vitamin $\mathrm{D}$ is indicated if the malabsorption cannot be relieved. High dose preparations of vitamin $\mathrm{D}$ appropriate in hypoparathyroidism $(1.25 \mathrm{mg})$ are known conventionally as calciferol, whereas those containing doses appropriate for nutritional osteomalacia and rickets are known as vitamin $\mathrm{D}$.

\section{Diphosphonates}

The diphosphonates are a group of analogues of pyrophosphate, taken by mouth, which inhibit bone resorption and formation. The only diphosphonate presently available is disodium etidronate (Didronel); it is used in Paget's disease to treat bone pain and less commonly neurological complications and immobilisation hypercalcaemia. The optimal dose is between 5 and $10 \mathrm{mg} / \mathrm{kg} /$ day. Higher doses (10 to $20 \mathrm{mg} / \mathrm{kg} /$ day) cause a more rapid reduction in bone turnover, but side effects -including diarrhoea and bone pain-are troublesome; bone mineralisation is impaired and spontaneous fractures may occur.

Only $5 \%$ of disodium etidronate is absorbed from the intestine, the remainder being excreted in the faeces. Absorption is impaired by food, particularly foodstuffs containing calcium and antacids, so that the drug is best given once daily while fasting, such as at bedtime. The drug is rapidly removed from the blood by renal excretion and adsorption on to bone surfaces. Increase in plasma phosphate concentrations is common and appears to be harmless.

There is no case for giving diphosphonates (or calcitonin) to symptomless patients with Paget's disease. The patients in whom medical treatment is most clearly indicated are those with bone pain (particularly if plasma alkaline phosphatase activity is appreciably increased) and those with progressive neurological impairment. In some cases it may be difficult to distinguish bone pain due to Paget's disease from that due to osteoarthropathy. In such cases a trial of treatment is appropriate. The diphosphonates should be stopped if the symptoms have not improved within two months.

\section{COMPARISON WITH CALCITONIN}

Calcitonin is now available either as the porcine preparation (Calcitare) or as a synthetic salmon calcitonin (Calsynar, Miacalcic). It is considered to be preferable to diphosphonates in the treatment of Paget's disease with recurrent fractures or non-union and also where there are pronounced osteolytic lesions. Calcitonin is more expensive and usually requires-at least initially-daily injections. Flushing occurs after injections in about a quarter of patients. About a quarter of patients develop resistance to treatment, in some as a result of the development of antibodies.

While the overall response to both these agents is similar, one is often effective where the other has failed. A typical course of treatment is for six months, after which with disodium etidronate the patient may remain symptomless for up to two years. Repeated courses may be given if relapse occurs. With calcitonin the period of remission is usually much shorter and maintenance treatment (often 100 IU weekly) is often given. A combination of calcitonin and disodium etidronate has been tried by several workers, but as yet there is no clear evidence that the combination is superior to either alone.

\section{Danazol}

Danazol (Danol) is a synthetic steroid, a derivative of ethis- $\frac{\text { p }}{z}$ terone, and suppresses the hypothalamic-pituitary-ovarian axis $\frac{3}{\mathbb{Q}}$ by inhibiting the output of gonadotrophins from the pituitary. $\stackrel{\Omega}{c}$ In addition, it may act by inhibiting binding of sex steroids to cellular receptors in target tissues and possibly by decreasing the synthesis of sex steroids. It has, therefore, been used to reduce hormonal stimulation to the endometrium and breasts in endo- $\mathbb{\Phi}$ metriosis and cystic disease respectively. It is the most effective form of medical treatment for endometriosis in part by tem- 으 porarily suppressing gonadal function. Side effects are common and predictable in view of its androgenic and anabolic activity.

Danazol is well absorbed with peak concentrations occurring? after two hours. It is metabolised in the liver and excreted in bile $\frac{\bar{\sigma}}{\bar{\omega}}$. and urine. Elimination half lives between five and 30 hours have $\frac{\bar{\sigma}}{\sigma}$ been reported. Like many hormones, however, the half life of $\stackrel{\mathbb{Q}}{\varrho}$ its biological activity does not correlate with the plasma half life, and it should be given twice to four times daily.

\section{ENDOMETRIOSIS}

When endometriosis is treated with danazol dysmenorrhoea isì

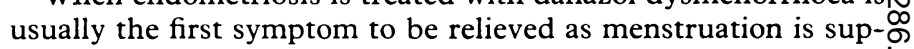
pressed. Relief of pain and dyspareunia occurs in over $75 \%$ హ of patients within three months. Increased conception rates may possibly follow treatment with danazol in infertile women with $\vec{\rightarrow}$ endometriosis. Those with severe or ovarian endometriosis do not have a complete response, but danazol is still valuable if given before and after surgery to promote healing of some lesions 5 and to limit the extent of surgery. After treatment the average ${ }_{-}^{N}$ annual recurrence rate is about $15 \%$. Most patients with mild to moderate disease have a prolonged remission and second courses of treatment may be given if necessary. Dosage $(200-800 \mathrm{mg} \overrightarrow{0}$ daily) depends on the severity. Treatment should be started ono the first day of a cycle to reduce the risk of irregular bleeding ${ }^{\omega}$ and unrecognised pregnancy. The initial daily dose is $400-600 \%$ $\mathrm{mg}$; this is reduced monthly to $200 \mathrm{mg}$ (or to a higher figure if amenorrhoea is not maintained). Treatment is continued for sixō months in patients with mild disease and up to a year in those⿳⺈冂大 with severe disease.

\section{MENORRHAGIA}

Danazol appreciably reduces blood loss in the first month, producing amenorrhoea usually by the third month of treatment. Long term treatment with $200 \mathrm{mg}$ a day commonly reduces menstrual loss to acceptable amounts with continuing menstruation in most patients. In most patients an effect continues for some months after treatment has been stopped.

\section{CYSTIC DISEASE OF THE BREAST}

More than $75 \%$ of patients with cystic disease of the breast respond to treatment with danazol. Pain, tenderness, and pre- $N$ menstrual engorgement are relieved or abolished within three months of starting treatment (usually in a dose of $400 \mathrm{mg}$ dailyo reducing to $200 \mathrm{mg}$ daily after one or two months). Nodularityo usually improves within six months. Some patients have a pro-t longed remission after the end of treatment. The possibility that? coexisting malignant disease of the breast is present should bet borne in mind. At present treatment is usually given only to $\vec{P}$ patients with severe symptoms.

\section{OTHER USES}

In men with gynaecomastia danazol has proved valuable in the management of those in whom underlying causes have beero 
excluded. In about two thirds of such patients a dose of 200$600 \mathrm{mg}$ daily relieves the severe and painful symptoms.

Danazol has been tried in precocious puberty, but further experience is needed before its use can be recommended. It has, however, proved effective in preventing attacks in patients with hereditary angioneurotic oedema by increasing the synthesis of the complement (C1)-esterase inhibitor.

\section{PRECAUTIONS}

The successful alleviation of endometriosis and dyspareunia is commonly followed by pregnancy after treatment with danazol has been stopped. Pregnancy should be excluded before danazol is given. Pronounced virilisation of female infants has been reported after the drug has been given to their mothers in pregnancy. It should not be given to patients with impaired cardiac, hepatic, or renal function, and caution is needed in patients with other conditions that may be adversely affected by fluid retention - such as epilepsy and migraine. A firm diagnosis and exclusion of malignant disease, particularly in patients with abnormal uterine bleeding, are essential. Until more is known about the long term effects of this agent, treatment should be for the shortest possible period.

\section{ADVERSE EFFECTS}

Many of the adverse effects are androgenic in nature and are reversed after treatment has stopped. Weight gain of $1-4 \mathrm{~kg}$ occurs in most patients; other common side effects include acne, seborrhoea, decreased breast size, irregular vaginal bleeding, and mild hirsutism. Muscle cramps affect up to a third of patients and menopausal symptoms, nausea, and rashes occasionally occur. Side effects are largely dose related and are seldom a problem in patients taking only $200 \mathrm{mg}$ daily.

\section{Bromocriptine}

Recent experience has firmly established the value of bromocriptine (Parlodel) in various conditions. It is an ergot alkaloid, a derivative of lysergic acid, and acts as a dopamine agonist. Bromocriptine inhibits both basal and stimulated prolactin secretion from the pituitary. It has some less specific dopamine like actions in other areas both in the central nervous system (basal ganglia, vomiting centre) and in blood vessels. These actions underlie the drug's use in Parkinson's disease and also explains some of its common side effects such as nausea and hypotension. Bromocriptine is well absorbed with peak concentrations occurring after two hours. It is almost completely metabolised in the liver and excreted in the bile. The effect of a single dose lasts about six to eight hours. Although its elimination half life is longer, the use of frequent small doses reduces side effects that are associated with high peak concentrations.

\section{INHIBITION OF LACTATION}

Given less than 12 hours postpartum bromocriptine prevents the start of lactation, without pain or breast engorgement, and restores prolactin to normal values within 48 hours. It is superior to all other methods of suppressing lactation, including oestrogens, but is considerably more expensive. Unlike oestrogens, it is also very effective in suppressing established lactation and breast engorgement. Bromocriptine $(2.5 \mathrm{mg}$ with meals $)$ is usually given twice daily for two weeks; some workers recommend that this dose should be given once daily for a third week to avoid the recurrence of lactation, which occurs in about a third of patients. Patients should be advised that fertility is rapidly restored. The first ovulation is likely within four weeks of delivery, and suitable contraceptive advice may be needed before the patient leaves hospital.

\section{HYPERPROLACTINAEMIA}

Hyperprolactinaemia is an important cause of anovulatory infertility, although the mechanism is not fully understood. A few patients with hyperprolactinaemia also have galactorrhoea. If hyperprolactinaemia due to other causes-for example, drugs such as phenothiazine and methyldopa-is excluded a chromophobe adenoma of the anterior pituitary is the most likely explanation. In women this is commonly a microadenoma and may show no sign of local expansion; in men the usual finding is an adenoma large enough to cause radiological changes and causing low gonadotrophin concentrations, hypogonadism, and infertility.

Bromocriptine (usually $5-7.5 \mathrm{mg}$ daily) rapidly restores prolactin concentrations to normal and ovulatory menstruation returns irrespective of the size of the tumour. There is some evidence, particularly in men, that tumours may shrink. Although bromocriptine seems to have no undesirable effects on the outcome of a subsequent pregnancy, patients require close supervision as pronounced expansion of the tumour during pregnancy may occur. Many patients with prolactin secreting tumours have been effectively controlled for several years, but the clinical course and outcome with long term treatment are not known.

In general, bromocriptine has no established place in the management of patients with infertility or impotence when there is no evidence of hyperprolactinaemia.

\section{PARKINSONISM}

The overall efficacy of bromocriptine in parkinsonism is similar to that of levodopa (plus decarboxylase inhibitor); few patients who are unresponsive to levodopa respond to bromocriptine. Although the effect of a single dose lasts longer than with levodopa, bromocriptine must be used in high doses (increasing gradually to $10-30 \mathrm{mg}$ three times daily) and is more expensive. Bromocriptine is usually restricted to patients who have intractable nausea or vomiting with levodopa (nausea with bromocriptine is usually less severe) or to those who show intolerable swings in response (on-off, end of dose akinesia), which often occur after several years' treatment with levodopa. Bromocriptine has two side effects that are largely confined to patients with parkinsonism; dyskinesia (orofacial grimacing, chorea) and hallucinations, particularly visual. The hallucinations may be related to the lysergic acid component of the molecule and may be accompanied by confusion and paranoid delusions.

\section{ACROMEGALY}

Bromocriptine causes a paradoxical lowering of growth hormone concentrations in most patients with acromegaly. Initial enthusiasm for its use in acromegaly has waned, since the suppression of growth hormone is rarely complete; most patients show only a partial clinical response and then only with doses as high as $20-60 \mathrm{mg}$ daily. It is mainly used in patients who are unsuitable for trans-sphenoidal surgery, as an adjunct to irradiation while awaiting response, and when these forms of treatment have been only partially effective.

\section{OTHER USES}

The use of bromocriptine for conditions such as premenstrual tension, mastalgia, and chronic hepatic encephalopathy has not been firmly established. Preliminary reports suggest that 
patients with benign breast disease who show a cyclical pain pattern may respond to $2.5 \mathrm{mg}$ twice daily.

\section{ADVERSE EFFECTS}

Nausea is a particularly common side effect and vomiting may occasionally limit the usefulness of bromocriptine. In most patients, however, these symptoms may be prevented by taking the drug with meals and beginning with a low $(1.25 \mathrm{mg})$ dose which is increased gradually over some days to weeks. Dizziness, postural hypotension, and constipation are other common side effects. Gastrointestinal haemorrhage rarely occurs in patients on high doses (over $10 \mathrm{mg}$ daily). Neuropsychiatric side effects are uncommon except in patients with Parkinson's disease.

We thank Dr John Mills for advice on gynaecological aspects of the drugs.

\section{Bibliography}

Dmowski WP. Endocrine properties and clinical application of danazol. Fertil Steril 1979;31:237-51.

A comprehensive review of the basic pharmacology and the endocrine effects of danazol. The selection of patients and practical application of treatment are discussed.

Haussler MR, Cordy PE. Metabolites and analogues of vitamin D: which for what ? f $A M A$ 1982;247:841-4.

A brief review of vitamin D metabolism with an outline of the main indications for and drawbacks of each of the metabolites and analogues used in clinical practice.

Hoffbrand BI, Jacobs HS. Danazol. Postgrad Med $\mathcal{F}$ 1979;55 suppl 5:7-94.

Conference proceedings describing clinical studies (many uncontrolled) with danazol in conditions where its efficacy is established (endometriosis, cystic disease of the breast) and where its use is controversial (unexplained infertility, premenstrual syndrome, and precocious puberty).

Kanis JA. Osteomalacia and chronic renal failure. $\mathcal{F}$ Clin Pathol $1981 ; \mathbf{3 4}$ 1295-307.
A useful review of the clinical, histological, and biochemical features of the bone disease of chronic renal failure and of its medical management.

Krane SM. Etidronate disodium in the treatment of Paget's disease of bone. Ann Intern Med 1982;96:619-25.

A review of the biochemical effects of the diphosphonates and of the clinical trials of different dosage regimens in Paget's disease. A discussion $\widehat{C}$ of the relative merits of etidronate disodium and calcitonin is included.

Lindholm J, Riishede J, Vestergaard S, Hummer L, Faber O, Hagen C. No effect of bromocriptine in acromegaly: a controlled trial. $N$ Engl $\mathcal{f} D$ Med 1981;304:1450-4.

Doubt cast on the efficacy of bromocriptine. The ensuing correspon- $m$ dence (305:1092-3) puts this study into perspective.

Madanes AE, Farber M. Danazol. Ann Intern Med 1982 ;96:625-30.

A review of the first five years' experience of the use of danazol in the United States. The prospective and comparative controlled trials are outlined as are the investigational uses of danazol in, for example, contraception and systemic lupus erythematosus.

Mansel RE, Wisbey JR, Hughes LE. Controlled trial of the antigonado- $\frac{\bar{T}}{\partial}$ trophin danazol in painful nodular benign breast disease. Lancet 1982; i:928-30.

Double blind study reporting objective and subjective improvement and suggesting that $200 \mathrm{mg}$ daily is adequate for most patients.

Parkes D. Bromocriptine. N Engl f Med 1979;301:873-8.

A review of the pharmacology and therapeutic uses of bromocriptine. $\overrightarrow{\vec{\omega}}$

Paterson CR. Vitamin D poisoning: survey of causes in 21 patients with hypercalcaemia. Lancet $1980 ; \mathrm{i}: 1164-5$.

An examination of the factors that contributed to episodes of hyper- 3 calcaemia in patients taking vitamin $D$. The cumulative nature of the drug and the importance of regular follow up are emphasised.

Prescott RWG, Johnston DG, Kendall-Taylor P, et al. Hyperprolactinaemia in men-response to bromocriptine therapy. Lancet $1982 ; \mathrm{i}: 245-8$.

Recent experience suggesting that bromocriptine may now be the treatment of choice for men with large tumours.

Sharman VL, Brownjohn AM, Goodwin FJ, et al. Long-term experience of $\vec{N}$ alphacalcidol in renal osteodystrophy. $Q \mathcal{F}$ Med 1982;51:271-8.

A cautious account of the use of alphacalcidol in 13 patients with renal $O$ failure undergoing regular haemodialysis. Hypercalcaemia was common, difficult to prevent, and potentially damaging.

Stevenson JC, Evans MA. Pharmacology and therapeutic use of calcitonin. Drugs $1981 ; 21: 257-72$.

A review of the physiology and pharmacological use of calcitonin. While its place in the management of Paget's disease is clearly described the other possible indications for its use are also outlined.

\section{Communicable Diseases}

\section{Penicillinase-producing Neisseria gonorrhoeae in Britain 1982}

Prepared by the Public Health Laboratory Service Communicable Disease Surveillance Centre and the Communicable Diseases (Scotland) Unit with the assistance of the Academic Department of Genitourinary Medicine, Middlesex Hospital Medical School.

In an analysis of infections due to penicillinase-producing strains of Neisseria gonorrhoeae reported in Britain during 197781 McCutchan and his coworkers showed that since these strains first appeared cases had doubled annually, primarily as a result of patients infected abroad. ${ }^{1}$ During 1981, however, the number of indigenous cases being reported began to exceed the imported cases, suggesting that the strains had become truly endemic here.

The data for 1982 are summarised in the table. The total for the year was 1033, compared with 433 in 1981. Infection was acquired abroad by 237 patients, 69 more than in the previous year but only $23 \%$ of the total, compared with $38 \%$ in 1981 and $52 \%$ in 1980 . Of the 237 patients, 102 had acquired the infection in the Far East (Thailand 51, Philippines 16, Singapore 9,
Hong Kong 7), 71 in West Africa (Nigeria 51), and 30 in Europe (West Germany 7, Netherlands 6, Spain 6, France 5). The pro- $\omega$ portional contribution of these three parts of the world to the total imported infections has changed little in the past three years. The consorts of a further 65 patients were infected abroad.

The infections regarded as indigenous-that is, when both the patient and consort were infected in Britain-show the greatest $\frac{0}{0}$ increase. The total in this category, 519 , is 354 more than in $\overrightarrow{\mathbb{D}}$ 1981. Of these 519 patients, 154 were stated to have contracted $\stackrel{?}{\mathbb{Q}}$ the infection in Greater London and a further 157 were reported $\varrho$ from laboratories in that area; Birmingham recorded 30 cases, Liverpool 28, Bristol 20, and Leeds 18, and many other areas 8 had smaller numbers of cases. The shift from importation to endemic transmission of penicillinase-producing Neisseria 